\title{
AN IN VITRO COMPARISON OF CEFOXITIN, A SEMI-SYNTHETIC CEPHAMYCIN, WITH CEPHALOTHIN
}

\author{
J. M. T. Hamilton-Miller, D. W. Kerry and W. Brumfitt \\ Department of Medical Microbiology, Royal Free Hospital, Grays Inn Road, \\ London, W.C.1., England
}

(Received for publication September 22, 1973)

\begin{abstract}
Cefoxitin, a semi-synthetic derivative of cephamycin C, is an analogue of cephalothin, and the two compounds were found to have many properties in common. A total of 232 strains of bacteria, representing 13 genera, isolated recently from clinical material, have been tested for sensitivity to both antibiotics. Against Gram-positive organisms, cephalothin was at least 8 times more active than cefoxitin, but against sensitive Gramnegative strains the activities of the two compounds were similar. Cefoxitin was active against a higher proportion of Bacteroides fragilis, Enterobacter spp. and Klebsiella spp. than was cephalothin, and was effective against 11 out of 12 indole-producing Proteus strains tested, all but one of which were resistant to cephalothin. Cefoxitin was remarkably stable in the presence of organisms which produce $\beta$-lactamase. Thus, on microbiological grounds, cefoxitin represents a significant advance over presently available conventional cephalosporins.
\end{abstract}

Cephamycins A, B and C are natural products with antibiotic activity produced by Streptomyces clavuligerus ${ }^{11}$ and $S$. griseus and S. lactamdurans ${ }^{21}$. While all three compounds are chemically closely related to the naturally occurring cephalosporin $C$, cephamycin $C$ has the closest resemblance ${ }^{1,3)}$. Cephamycin $\mathrm{C}$ has been converted to a compound called cefoxitin, which bears the same relationship to the parent compound as does cephalothin to cephalosporin $\mathrm{C}^{4)}$. It was thought to be of interest to compare the antimicrobial activities in vitro of cefoxitin and cephalothin.

\section{Methods and Materials}

Antibiotics

Cefoxitin (sodium salt) was supplied by Dr. C. M. Martin, Merck, Sharp and Dohme, and cephalothin (Keflin) was obtained from Eli Lilly.

Bacterial Strains

Virtually all the strains used had been isolated from clinical material sent to these laboratories during the period April to July 1973 and are therefore representative of organisms encountered in hospital practice in Great Britain.

The $B$. fragilis strains were incubated for 42 hours at $37^{\circ} \mathrm{C}$ in cooked meat medium, while all other organisms were incubated for 18 hours at $37^{\circ} \mathrm{C}$ in digest broth.

Determination of M. I. C.

A doubling dilution method in agar was used, with Difco Brain-Heart Infusion (BHI) agar as the medium. When Streptococcus faecalis and $B$. fragilis were being tested, lysed horse blood was added to the medium to give a final concentration of $4 \%(\mathrm{v} / \mathrm{v})$. Tests with cefoxitin and cephalothin were always done in parallel. For all non-swarming strains, circular $(8.5 \mathrm{~cm}$ diameter) plates were used, containing $15 \mathrm{ml}$ of medium; each of these plates was streak inoculated radially with a total of 10 strains, using a $1 / 100$ dilution in water of an overnight 
broth culture (see above), applied with a standard loop, and incubated at $37^{\circ} \mathrm{C}$ overnight (for 42 hours using the BBL Gaspak system in the case of $B$. fragilis). For the Proteus strains, the medium $(50 \mathrm{ml})$ was poured into square plates $(10 \mathrm{~cm})$ divided into 25 compartments, each compartment being inoculated drop-wise with $20 \mu \mathrm{l}$ of diluted culture. M. I. C. was taken as the lowest concentration of antibiotic which prevented growth completely.

Effect of Inoculum Size

M. I. C. were determined as described above, except four series of plates were used for each antibiotic, inocula being undiluted overnight culture and the following dilutions of each culture: $-2,-4$ and -5 . Viable counts were made of the latter cultures.

Effect of Medium $\mathrm{pH}$

Samples of double-strength BHI agar were mixed with equal volumes of double-strength MCIlvaINE's phosphate-citrate buffer ${ }^{5)}$ of $\mathrm{pH}$ values $4,5,6$ or 8 and the resulting media were used to prepare serial dilutions of cefoxitin and cephalothin. Plates were inoculated with $1 / 100$ dilutions of overnight cultures for M. I. C. determination. In a separate experiment, the $\mathrm{pH}$ of the resulting media were found to be $4.8,5.6,6.3$ and 7.7 respectively. Results were compared with those obtained using BHI agar ( $\mathrm{pH}$ 7.4) made up according to the manufacturer's instructions.

Effect of Medium Composition

M. I. C. were determined as above using the following media: minimal salts agar ${ }^{6)}$, peptone water (Oxoid) $+1.5 \%$ No. 3 agar, Difco Antibiotic Medium No. 2 (Penassay Base agar), and TodD-HewitT Broth (Oxoid) $+1.5 \%$ No. 3 agar. When the first medium was used plates were read after 18 hours then reincubated for 24 hours and read again. Results were compared with those obtained using BHI agar.

Destruction of Antibiotic

Strains under test which were resistant to one or other antibiotic were grown overnight in $10 \mathrm{ml}$ volumes of digest broth, and bacteria were spun down in centrifuge tubes and washed in MCIlvaINE's phosphate-citrate buffer $\mathrm{pH}$ 7. They were then resuspended in the same buffer containing $200 \mu \mathrm{g} / \mathrm{ml}$ of either cephalothin or cefoxitin, and incubated for 5 hours at $37^{\circ} \mathrm{C}$. After this, the suspensions were centrifuged, and the antibiotic concentration in the suspernatant fraction was estimated by bioassay, using the disk technique with Staphylococcus aureus MB as indicator ${ }^{7)}$. An organism sensitive to both compounds (Klebsiella aerogenes 037 ) was used as control. In some cases organisms were induced by growth in the presence of $200 \mu \mathrm{g} / \mathrm{ml}$ cefoxitin or cephalothin.

Correlation between M. I. C. and Size of Zone of Inhibition

Paper discs of diameter $6 \mathrm{~mm}$, containing $30 \mu \mathrm{g}$ of cefoxitin (kindly provided by Dr. C. M. MARTIN), were placed on plates containing Direct Sensitivity Agar (Oxoid) each of which had been flood-inoculated with a $1 / 100$ dilution of an overnight culture of the organism under test. The plates were incubated at $37^{\circ} \mathrm{C}$ overnight and the diameter of each zone of inhibition was read using calipers.

\section{Growth Curves}

Staph. aureus Oxford and Escherichia coli 877 were used in these experiments; the M. I. C. for cephalothin were 0.31 and $5 \mu \mathrm{g} / \mathrm{ml}$ and for cefoxitin 2.5 and $5 \mu \mathrm{g} / \mathrm{ml}$, respectively. Overnight cultures in Tryptic Soy broth (Difco) $(0.3 \mathrm{ml})$ were inoculated into tubes each containing $9.6 \mathrm{ml}$ of the same medium. The tubes were incubated at $37^{\circ} \mathrm{C}$ and read at intervals on a EEL nephelometer; when the cultures were about half way through the logarithmic phase (galvanometer reading 30 40), $0.1 \mathrm{ml}$ amounts of Tryptic Soy broth containing various concentrations of antibiotics were added, the tubes mixed at a vortex stirrer and readings continued.

\section{Effect of Anaerobiosis}

M. I. C. determinations were carried out, as above, in duplicate. One set of plates was incubated in an atmosphere of hydrogen and the other aerobically. 


\section{Results}

Comparative Antimicrobial Activities of Cephalothin and Cefoxitin

The results for all the M. I. C. tests are shown in Tables 1 and 2. Against Staphylococcus aureus cephalothin was some eight times more active than cefoxitin, but it should be noted that the majority of strains were inhibited by $2.5 \mu \mathrm{g} / \mathrm{ml}$ of the latter compound and all by $5 \mu \mathrm{g} / \mathrm{ml}$. These concentrations are well within the serum levels obtained after administration of the drug to humans ${ }^{7)}$. There was no difference in sensitivity between organisms that were penicillin-sensitive and those which were penicillin-resistant. Against Streptococcus faecalis cefoxitin was again less active than cephalothin, having an M.I.C. between four and eight times (or greater) that of cephalothin. This finding that enterococci are relatively resistant to cephalosporins is in line with the results of other workers ${ }^{8)}$.

While the majority of $E$. coli strains were sensitive to cephalothin, it should be noted that two required $40 \mu \mathrm{g} / \mathrm{ml}$ or more in order to inhibit them, whereas all 40 strains were sensitive to cefoxitin, which generally speaking showed twice the activity of cephalothin. Two of the

Table 1. Activity of cephalothin against Gram-positive bacteria

\begin{tabular}{|c|c|c|c|c|c|c|c|c|}
\hline \multirow{2}{*}{ Organism } & \multirow{2}{*}{$\begin{array}{c}\text { Number of } \\
\text { strains tested }\end{array}$} & \multirow{2}{*}{ Drug } & \multicolumn{6}{|c|}{$\begin{array}{l}\text { Number of strains inhibited by indicated } \\
\text { concentration }(\mu \mathrm{g} / \mathrm{ml})\end{array}$} \\
\hline & & & 0.16 & 0.32 & 0.63 & 1.25 & 2.5 & 5 \\
\hline \multirow[t]{2}{*}{ Staphylococcus aureus } & 27 & $\begin{array}{l}\text { Cephalothin } \\
\text { Cefoxitin }\end{array}$ & 6 & 20 & 1 & 1 & 23 & 3 \\
\hline & & & 20 & 40 & 80 & 160 & $>160$ & \\
\hline Streptococcus faecalis & 19 & $\begin{array}{l}\text { Cephalothin } \\
\text { Cefoxitin }\end{array}$ & 14 & $\begin{array}{l}5 \\
1\end{array}$ & & & 18 & \\
\hline
\end{tabular}

Table 2. Activity of cephalothin and cefoxitin against Gram-negative bacteria

\begin{tabular}{|c|c|c|c|c|c|c|c|c|}
\hline \multirow{2}{*}{ Organism } & \multirow{2}{*}{$\begin{array}{l}\text { Number of } \\
\text { strains tested }\end{array}$} & \multirow{2}{*}{ Drug } & \multicolumn{6}{|c|}{$\begin{array}{c}\text { Number of strains inhibited by indicated } \\
\text { concentration }(\mu \mathrm{g} / \mathrm{ml})\end{array}$} \\
\hline & & & 2.5 & 5 & 10 & 20 & 40 & $>40$ \\
\hline Escherichia coli & 40 & Cephalothin & 2 & 8 & 23 & 7 & 1 & 2 \\
\hline Alkalescens spp. & 3 & Cefoxitin & 2 & 23 & 17 & & & 1 \\
\hline \multirow[t]{2}{*}{ Proteus mirabilis } & 27 & Cephalothin & 2 & 7 & 11 & 7 & & \\
\hline & & Cefoxitin & 1 & 3 & 20 & 3 & & \\
\hline \multirow{2}{*}{$\begin{array}{l}\text { Indole-positive } \\
\text { Proterus spp. }\end{array}$} & 12 & Cephalothin & & & & 1 & & 11 \\
\hline & & Cefoxitin & 1 & 3 & 3 & 4 & & 1 \\
\hline \multirow[t]{2}{*}{ Enterobacter spp. } & 23 & Cephalothin & 1 & & 3 & & 1 & 18 \\
\hline & & Cefoxitin & 1 & & 5 & 2 & 2 & 13 \\
\hline \multirow[t]{2}{*}{ Klebsiella spp. } & 34 & Cephalothin & 8 & 10 & 7 & 4 & & 5 \\
\hline & & Cefoxitin & 4 & 24 & 6 & & & \\
\hline \multirow[t]{2}{*}{ Bacteroides fragilis } & 10 & Cephalothin & 1 & & 1 & & 2 & 6 \\
\hline & & Cefoxitin & 1 & & 3 & 2 & 1 & 3 \\
\hline \multirow[t]{2}{*}{ Acinetobacter spp. } & 5 & Cephalothin & & & 3 & & & 2 \\
\hline & & Cefoxitin & & & 4 & & & 1 \\
\hline
\end{tabular}


three Alkalescens strains tested were sensitive to both compounds.

Cefoxitin was the better antibiotic against Klebsiella strains; all 34 tested were inhibited by $10 \mu \mathrm{g} / \mathrm{ml}$ or less, whereas $9(26.4 \%)$ required $20 \mu \mathrm{g} / \mathrm{ml}$ or more of cephalothin to inhibit growth.

Both antibiotics were poorly active against Enterobacter spp.; of the 23 strains tested, 2 were $E$. hafnia, $3 \mathrm{E}$. aerogenes and $18 \mathrm{E}$. cloacae. Thirteen strains (all E. cloacae) were resistant to $40 \mu \mathrm{g} / \mathrm{ml}$ of cefoxitin, and these same strains and 5 others $(3$ E. cloacae and 2 E. aerogenes) were also resistant to $40 \mu \mathrm{g} / \mathrm{ml}$ of cephalothin. Taking $20 \mu \mathrm{g} / \mathrm{ml}$ as the division between sensitivity and resistance (see below), cefoxitin was active against 8 strains (34.7\%), cephalothin against $4(17.3 \%)$. Both E. hafnia strains were sensitive to both antibiotics.

There was very little difference between the activities of the two antibiotics against Proteus mirabilis strains; there was a greater spread of M.I.C.s with cephalothin than with cefoxitin but both ranges centred around $10 \mu \mathrm{g} / \mathrm{ml}$. During the course of these experiments it was observed that the concentration of antibiotic which prevented swarming of these $P$. mirabilis strains was considerably less than the concentration required to inhibit normal growth; this observation suggests that the long swarming forms may be more sensitive to $\beta$-lactam antibiotics than the normal vegetative forms. The indole-producing Proteus strains, of which 12 were tested (5 P. vulgaris, 5 P. morgani, 2 P. rettgeri), provided a striking example of the superiority of cefoxitin over cephalothin. Only one of these strains was inhibited by $20 \mu \mathrm{g} / \mathrm{ml}$ of the latter, the remainder being resistant to $40 \mu \mathrm{g} / \mathrm{ml}$; on the other hand, only one strain (P. morgani 185) was resistant to $40 \mu \mathrm{g} / \mathrm{ml}$ of cefoxitin, while more than half the strains tested (including all the P. vulgaris) were inhibited by $10 \mu \mathrm{g} / \mathrm{m} 1$.

Against $P$ seudomonas aeruginosa both antibiotics showed very little activity; however, whereas cephalothin failed to inhibit the growth of any of the 29 strains tested at a concentration of $1 \mathrm{mg}$ per $\mathrm{ml}, 9$ were inhibited by the same concentration of cefoxitin.

Against the anaerobic species Bacteroides fragilis cefoxitin was clearly superior to cephalothin, although the activity of both antibiotics was rather low. Six of the strains tested were inhibited by $20 \mu \mathrm{g} / \mathrm{ml}$ of cefoxitin whereas with cephalothin only two were so inhibited. One strain of Serratia was also found to be more sensitive to cefoxitin (M. I. C. $=20 \mu \mathrm{g} / \mathrm{ml}$ ) than to cephalothin (M. I. C. $>80 \mu \mathrm{g} / \mathrm{ml}$ ), as was also a strain of Aeromonas (M. I. C. for cefoxitin $1.3 \mu \mathrm{g} / \mathrm{ml}$, for cephalothin $20 \mu \mathrm{g} / \mathrm{ml}$ ); the situation was reversed with a Citrobacter strain, for which M. I. C. for cephalothin was $40 \mu \mathrm{g} / \mathrm{ml}$ and for cefoxitin $>40 \mu \mathrm{g} / \mathrm{ml}$.

\section{Destruction of Antibiotic}

In all, 147 strains belonging to the family Enterobacteriaceae were tested for sensitivity to the two antibiotics, of which 38 were resistant to $40 \mu \mathrm{g} / \mathrm{ml}$ of cephalothin and 17 to $40 \mu \mathrm{g} / \mathrm{ml}$ of cefoxitin. Twenty-six of the cephalothin-resistant strains were tested for their ability to destroy the antibiotic, and in all cases some destruction was observed, which was usually total. All 17 cefoxitin resistant strains were likewise tested for cefoxitin destruction; this was observed in only a single case, with $E$. aerogenes 448 , and this was only after the organism had been induced by growth in the presence of $200 \mu \mathrm{g} / \mathrm{ml}$ of either cefoxitin or cephalothin. Representative cultures of $P$. aeruginosa and Streptococcus faecalis did not destroy cefoxitin. 
Effect of $\mathrm{pH}$ on Biological Activity

Considerable changes (up to thousandfold) in hydrogen ion concentration had only small effects on M.I.C. for the two antibiotics. Against coliform organisms no differences could be discerned between cephalothin and cefoxitin. Thus against four strains of Klebsiella and five of E. coli, M. I. C.s were not significantly different at $\mathrm{pH} 7.7,7.4$ and 6.3, while at pH 5.6 M. I. C.s were often only one dilution higher; against the Klebsiella strains the activity of both compounds at $\mathrm{pH} 4.8$ was generally four fold less than at neutrality. The E. coli strains failed to grow on media at the lowest $\mathrm{pH}$ levels. Cefoxitin had virtually identical activity against 10 Staph. aureus strains at pHs 4.8, 5.6 and 6.3; none of the strains used in these experiments would grow in BHI agar made up in $\mathrm{pH} 8$ buffer. Cephalothin showed a two to four fold decrease in M. I. C. at $\mathrm{pH}$ 4.8. The staphylococcal strains all grew rather poorly at the more acid $\mathrm{pH}$ values even after 48 hours incubation at $37^{\circ} \mathrm{C}$.

\section{Effect of Anaerobiosis}

Only minor differences in the M. I. C. of cephalothin and cefoxitin against $5 \mathrm{E}$. coli and 5 Klebsiella strains were observed under aerobic and anaerobic conditions. In general, the antibiotics were more active in the absence of oxygen, 6 and 9 of the 10 strains having M. I. C. one dilution lower for cephalothin and cefoxitin respectively.

\section{Inoculum Size Effect}

Using 5 E. coli and 5 Klebsiella strains, the same M.I.C.s were obtained using inocula diluted $10^{-2}$ and $10^{-4}$ and $10^{-5}$, with each antibiotic. Increasing the inoculum size to that obtained by using a neat culture (i.e. between $2.5 \times 10^{6}$ and $1.3 \times 10^{7}$ organisms) resulted in an increase in the M.I.C. of between two and eight fold for cephalothin $(m e a n=6)$ and between two and four fold for cefoxitin (mean=2.6). This difference is significant $(P<0.01)$.

Using 10 strains of Staph. aureus (five sensitive and five resistant to benzylpenicillin), increasing the inoculum size 10,000 fold, i.e. from a $10^{-4}$ dilution to undiluted culture, increased the M. I. C. of each drug by a maximum of only two fold.

\section{Effect of Medium}

Using 10 coliform organisms (5 Klebsiella and 5 E. coli strains) virtually identical results (i.e. no more than two-fold variation) were obtained for both antibiotics on the four complex media. There was slightly more variation when minimal salts medium was used, the M.I.C.s appearing to be consistently lower than the highest observed, but in no case was any overall difference found to be greater than four fold.

\section{Correlation between Zone Size and M.I. C.}

This relationship was analysed using 100 Gram-negative strains with M. I. C. $<20 \mu \mathrm{g} / \mathrm{ml}$. Overall correlation was significant $(P<0.001)$, although the correlation coefficient was relatively low $(r=-0.371)$. The reason for the low value of the correlation coefficient was sought by analysing various groups of organisms separately. For $33 \mathrm{E}$. coli and 16 Klebsiella strains the correlation was found to be not significant $(P>0.3$ in both cases), but for 39 Proteus spp. strains 
and 12 'miscellaneous' organisms (4 Enterobacter spp., 4 Acinetobacter spp., 2 Alkalescens spp., 1 Citrobacter spp. and 1 Aeromonas) correlation coefficients were much higher ( -0.697 and -0.927 respectively), yielding significant linearity. Why the Klebsiella spp. and E. coli gave aberrant results is not clear; when strains were retested at random, zone sizes were within $10 \%$ of the size originally found. It has recently been suggested that it is not valid to construct one common regression line for different species ${ }^{9 !}$.

Notwithstanding the above, only 4 of the 100 strains tested gave zone sizes of less than $20 \mathrm{~mm}$, so that a zone of this size can be taken as indicative of sensitivity, and the few resistant organisms that were tested (M. I. C. $>40 \mu \mathrm{g} / \mathrm{ml}$ ) gave either a very small zone or none at all.

\section{Effect on Bacterial Growth}

Both antibiotics had a lytic effect against $E$. coli 877 in static culture, which started to occur within not more than one hour after the addition of the antibiotic. The zone phenomenon characteristic of benzylpenicillin was observed with both compounds: with cephalothin, lysis was more pronounced with $25 \mu \mathrm{g} / \mathrm{ml}$ than with $30 \mu \mathrm{g} / \mathrm{ml}$, and with cefoxitin $15 \mu \mathrm{g} / \mathrm{ml}$ was more rapidly lytic than was $20 \mu \mathrm{g} / \mathrm{ml}$. Against this strain, $7 \mu \mathrm{g} / \mathrm{ml}$ of cefoxitin caused cessation of growth, while $20 \mu \mathrm{g} / \mathrm{ml}$ of cephalothin was required for the same effect. These figures should be compared with the overnight M. I. C. in agar of $5 \mu \mathrm{g} / \mathrm{ml}$ for both compounds. Lysis was less pronounced with Staph. aureus Oxford; significant lysis was, however, observed with concentrations of cefoxitin between 2 and $7 \mu \mathrm{g} / \mathrm{ml}$ (cf. overnight M. I. C. of $2.5 \mu \mathrm{g} / \mathrm{ml}$ ) which started between 100 and 200 minutes after the addition of the antibiotic. With equivalent concentrations of cephalothin $(0.2 \sim 1 \mu \mathrm{g} / \mathrm{ml})$ there was little or no lysis, merely a cessation of growth some 3 hours after the antibiotic had been added.

\section{Discussion}

The advent of semi-synthetic penicillins such as methicillin and cloxacillin, and of the cephalosporins, which are virtually stable towards staphylococcal $\beta$-lactamase, has largely solved the problem of the "penicillin-resistant" Staph. aureus strains. However, the role of $\beta$-lactamase activity in the resistance of Gram-negative organisms to penicillins and cephalosporins is by no means as clear. There can be no doubt that the possession of an active $\beta$-lactamase will enhance the resistance of a strain to a labile antibiotic, but many organisms which produce $\beta$-lactamases are also of high intrinsic resistance. Clearly, introduction of $\beta$-lactam antibiotics which are not affected by $\beta$-lactamases can only be to the good, but such substances cannot be expected to provide the ultimate antimicrobial answer.

A new semi-synthetic cephalosporin compound, cephanone, has been claimed to offer resistance to $\beta$-lactamases, but such resistance is not very marked and its in vitro performance has been somewhat disappointing ${ }^{10,11)}$. The degree of stability to $\beta$-lactamases shown by cephamycin C, however, appears to be of an entirely different order, with the result that this compound is virtually untouched by $\beta$-lactamases which rapidly destroy cephalothin and cephaloridine, such as those from Enterobacter spp. Serratia spp., and Klebsiella spp. ${ }^{12,13)}$. By analogy with the cephalosporins, replacement of the $\alpha$-aminoadipoyl side chain of cephamycin $C$ with the thienyl group of cefoxitin would be expected not only to increase further the stability to $\beta$ lactamases of the latter compound but also to improve its biological activity.

The work described in the present paper shows that this expectation has, indeed, been fulfilled. The antimicrobial activity of cefoxitin compares very favourably with that of cephalothin: against $B$. fragilis, Klebsiella spp. and Enterobacter spp. strains the advantage is 
only marginal (although distinct) but against the indole-producing Proteus spp. it is very marked. It should be pointed out, however, that strains of the latter species are not common in this country, except during outbreaks of cross-infection. Cefoxitin resembles cephalexin in having virtually identical activity against Gram-positive and Gram-negative bacteria; however, cefoxitin has a broader spectrum than does cephalexin. The most remarkable property of cefoxitin is, however, without doubt its great resistance to $\beta$-lactamases. Only one of 17 resistant coliform organisms tested destroyed cefoxitin, while cephalothin was broken down, to a greater or lesser extent, by all the resistant strains tested. It is clear from the above that Enterobacter spp. and Ps. aeruginosa owe their resistance to an intrinsic mechanism.

The mode of action of 7-methoxycephalosporins, which are very closely related in chemical terms to the cephamycins, has been shown to be the same as that of the cephalosporins, that is inhibition of cellwall transpeptidation ${ }^{14)}$. We have shown here that cefoxitin has lytic activity against growing cells, and shows a classic penicillin-like "zone effect". In view of its favourable microbiological and pharmacokinetic properties, cefoxitin must be a strong candidate for clinical trial.

\section{References}

1) Nagarajan, R.; L. D. Boeck, M. Gorman, R. L. Hamill, C. E. Higgens, M. M. Hoehn, W. M. Stark \& J.G. Whitney: $\beta$-Lactam antibiotics from Streptomyces. J. Amer. Chem. Soc. 93: 2308 2310, 1971

2) Stapley, E. O.; M. Jackson, S. Hernandez, S. B. Zimmerman, S. A. Currie, S. Mochales, J. M. Mata, H. B. Woodruff \& D. Hendlin: Cephamycins, a new family of $\beta$-lactam antibiotics. I. Production by Actinomycetes, including Streptomyces lactamdurans sp. n. Antimicr. Agents \& Chemoth. 2: 122 131, 1972

3) Albers-Schönberb, G.; B. H. Arison \& J. L. Smith: New $\beta$-lactam antibiotics: structure determination of cephamycin A and B. Tetrahedron Lett. 1972: 2911 2914, 1972

4) Karady, S.; S. H. Pines, L. M. Weinstock, F. E. Roberts, G. S. Brenner, A. M. Hoinowski, T. Y. Cheng \& M. Sletzinger: Semi-synthetic cephalosphorins via a novel exchange reaction. J. Amer. Chem. Soc. 95: 1410 1411, 1972

5) Scientific Tables, 6th Edition, ed. by K. Diem (Documenta Geigy, 1962)

6) Davis, B. D. \& E. S. Minglolr: Mutants of Escherichia coli requiring methionine or vitamin $\mathrm{B}_{12}$. J. Bact. 60: 17 28, 1950

7) Kosmidis, J.; J. M. T. Hamilton-Miller, J. N. G. Gilchrist, D. W. Kerry \& W. Brumfitt: Comparative clinical pharmacology of cefoxitin and cephalothin in humans. Proc. VIII Int. Congr. Chemother., Athens, Abs. A-152, 1973

8) Garrod, H. \& F. O'Grady: Antibiotic and Chemotherapy (3rd edition) p. 88. E. \& S. Livingstone, Edinburgh, 1971

9) Kaufmann, H.; H. Neussel \& G. Linzenmeier: Probleme der Empfindlichkeittestung von Bakterien mit dem Agar-Diffusionstest. Arzneim. Forsch. 23: 743 746, 1973

10) Wick, W.E. \& D. A. PRESTON: Biological properties of three 3-heterocyclic-thiomethyl cephalosporin antibiotics. Antimicr. Agents \& Chemoth. 1: 221 234, 1972

11) NeU, H. C. \& E. B. Winsell: In vitro studies of cephanone, a 3-heterocyclic-thiomethyl cephalosporin antibiotic. J. Antibiotics 26: 153 156, 1973

12) Daoust, D. R.; H. R. Onishi, H. Wallick, D. Hendlin \& E. O. Stapley: Cephamycins, a new family of $\beta$-lactam antibiotics: antibacterial activity and resistance to $\beta$-lactamase degradation. Antimicr. Agents \& Chemoth. 3: 254 261, 1973

13) Miller, A. K.; E. Celozzi, B. A. Pelak, E. O. Stapley \& D. Hendlin: Cephamycins, a new family of $\beta$-lactam antibiotics. III. In vitro studies. Antimicr. Agents \& Chemoth. 2: 281 286, 1972

14) Ho, P. P. K.; R. D. Towner, J. M. Indelicato, W. J. Wilham, W. A. Spitzer \& G. A. Koppel: Biochemical and microbiological studies on 7-methoxycephalosporins. J. Antibiotics 26: 313 314, 1973 